\title{
Hypothesis-Generation and Innovativeness. A Videography- based Analysis of Lay Hypothesis- Generation in Secondary-School Education
}

\author{
Thomas Jekel and Marissa Lehner \\ Department of Geography and Geology \& School of Education, \\ University of Salzburg, Austria
}

\begin{abstract}
Aspects of fostering innovativeness within secondary-school geography education have scarcely been studied. We therefore have little knowledge of where to start when teaching and learning to use spatialized and animated data to develop innovations. This study reports on lay users' strategies to develop hypotheses within the Gapminder world environment using screencapture (OCAM and QuickTime Player) and oral descriptions of hypothesis-generation for CO2 emissions. Videography as a method based on ethnography (Tuma et al., 2013) is used for analysis and interpretation. These lay strategies form the basis of modified teaching processes that actually foster innovativeness within the technical knowledge domain of STEM subjects.
\end{abstract}

\section{Keywords:}

innovation, education, hypothesis generation, videography

\section{Introduction}

In 2013, Larissa Shavinina (ed.) published the Routledge International Handbook of Innovation Education. While the work as a whole goes to great lengths to explain concepts, psychological basics and tests, Science, Technology, Engingeering and Mathematics (STEM) education, fostering gifted students and innovators, as well as many other considerations, the spatial dimension of innovations is conspicuous by its absence. This may be due to the idea of the spatial dimension being a given; but it misses out on the potential of spatial disciplines to contribute to innovation and innovativeness. At the same time, it may be argued that geography education has paid little attention to a conceptualization of innovation education, or education for innovativeness. If the term 'innovation' was used in the field, it usually referred to bringing (mostly technical or procedural) innovation into schools, not actively supporting innovation capabilities at the level of individual students (Jekel, Ferber \& Stuppacher, 2015). However, since 2013, supporting innovativeness has started to receive some attention in geography education (Gryl, 2013; Scharf, Schmitz \& Gryl, 2016). 
The current discussion is in parallel with the development of multiple tools that allow the collection, aggregation and visualization of data to be implemented by lay users (Gartner, 2009, Sui, Elwood \& Goodchild, 2013). Two major possibilities and roles for spatial representations in innovation may be identified here. Firstly, spatial representations may be considered a tool to actively change the meaning of space, as is the case in the spatial citizenship approach (Gryl \& Jekel, 2012; Jekel, Gryl \& Schulze, 2015). As well as reconstructing meanings of space, spatial representations may also lead to the formation of a 'new' political subject, a politically aware citizen (Gordon, Elwood \& Mitchell, 2016). Within the innovation process, spatial representations are used as powerful modes of communication, paired with reflexivity. Secondly, spatial representations may be considered a starting point for the identification of problems and their structuring. This is the main argument of the spatial thinking approach (NCA, 2006), where it is subsumed under spatial reasoning. In this contribution, following on from Jekel (2014), spatial representations are presented as a tool for hypothesis-generation as a starting point for innovation. The two approaches are not mutually exclusive, and may be combined within an innovation process.

The question here is whether innovativeness can actually been learned or taught. This paper gives a brief overview of a variety of theoretical propositions from the innovativeness / innovation education literature. It then links creativity to the idea of hypothesis-generation. If hypothesis-generation from spatial data and representations can actually be considered an important component of creativity, the lay generation of hypotheses from representations of data is an important starting point for learning processes. This contribution therefore looks into how student lay users aged 16-17, without prior instruction, develop their hypotheses based on spatial data visualized through animated graphs. It suggests that the everyday generation of hypotheses is the starting point for instructional designs. These designs then support the formalization of hypothesis-generation and supply students with strategies for the development of their hypotheses.

\section{Innovativeness, Spatial representation and hypothesis-generation}

Both VGI tools and interactive interfaces lead to a wide variety of new options for the lay user for carrying out visual analytics.

'Spatio-temporal analysis is not something that only highly qualified specialists do. All people become spatio-temporal analysts when planning their journeys, looking for jobs or searching for suitable places to live and visit' (Andrienko et al., 2010, p. 1579). Even for trivial games, we need spatial analytics: think of a game of pick-up-sticks, where your strategies clearly depend on your powers to analyse visually, and think spatially. Your strategy is successful if you are able to detect links and non-links between sticks, and is especially successful if you detect them earlier than other players do (Sinton, 2013). Whenever we assess a situation, we have assumptions about spatial settings, about resources and power in mind. Within technological questions and the sciences, many of our ideas are based on the analysis of data and the search for patterns and laws guiding a specific phenomenon. 
For years, most of these analyses had to do with statistics, which both scholars as well as secondary-school students find difficult to decipher, let alone interpret. Visual analytics here can be seen as a new toolset:

Visual analytics is different from 'standard' approaches to analysis. It is based on the assumption that interactive visual representations can amplify human natural capabilities for detecting patterns, establishing links and making inferences. (Andrienko et al., 2010, p. 1587).

In 2013, Gryl defined three major dimensions of innovativeness as the ability to innovate:

- The reflexive and creative act of transforming an existing situation and existing routines into a problem;

- The creative act of invention, based on hypotheses and oriented towards problem solving;

- The implementation of the invention through communication and participation in discourse.

Gryl also hinted at a more technical and a more societal domain of innovation. In this paper, we clearly position ourselves within technical innovation. We believe that, at secondaryschool level, a 'trimmed' visual analytics approach can support the act of invention and its implementation through communication in the above categories of innovativeness. Within the technical domain, our approach can be seen as one that transforms an existing situation into a problem, and it provides first assumptions about causal links between various dimensions of the situation. We do not, however, suggest that the visualizations are directly linked to the creative act, but they may pre-structure data as a basis for the creative act. If, for example causes for $\mathrm{CO}_{2}$ emissions are identified and deemed a problem, the creative act lies in the social and political sphere as to how to combat the causes. The research presented here clearly refers only to the first of Gryl's three dimensions of innovativeness.

\section{Research on learning with diagrams / animated graphs}

Considering the history of animated and interactive graphs, it is quite astounding that there is little research on actual learning processes that use graphs. In many cases, learning from graphs - in the form of the map communication model - was looked into (Traun et al., 2013). And while suspected better learning from animated graphs has been at the centre of some studies, these produced no ground-breaking results one way or the other (Hegarty, 2004, p. 344). However, interactivity was deemed very much to be a significant positive influence on learning outcomes. This led to the hypothesis that

the task of generating diagrams while reading would promote richer mental model construction than the task of generating summaries or simply reading the text. This bypothesis was confirmed; that is, those who generated diagrams outperformed those who generated summaries in terms of their resulting conceptual representations of the domain. (Gobert \& Clement, 1999, p. 48)

In this case, actively producing diagrams helped learning processes, where the diagram was not at the centre of learning but a tool for learning borrowed from a different domain. 
A second line of thinking regards the nature of the learning we expect to take place. Do we learn about diagrams, from diagrams or with diagrams? (A similar discussion has been prevalent in the Learning with GIS community; see Gryl \& Jekel, 2012.) Tippet (2016, p. 731) states that

early research on representations typically considered viewing/reading of pre-constructed representations, but taking a constructive-interpretive perspective of language moves the problem from that fairly well-defined area into an exploratory space, as comparatively little is known about what happens as students generate/construct their own visual representations.

It is precisely this exploratory space, which students go to as soon as they have to build hypotheses, reason from data, and their own visualizations, that this study looks at, based on the use of Gapminder. Earlier work has looked mainly at the outcome of the hypothesisgeneration process (see e.g. Lang, 2012), while we try to explore the process that leads to assumptions about real-world phenomena.

The main research questions, consequently, are as follows:

1. Are there common strategies (e.g. search strategies, or use of interactive animation for reasoning) among lay users?

2. Are explicitly spatial arguments used to explain hypotheses?

3. Are visualizations used in the argumentation of the hypotheses?

4. What role does pre-knowledge play in the identification of indicators explaining a specific phenomenon?

We believe that answers to these questions are of help in devising teaching strategies that support a constructivist approach to learning that is still, however, data-based.

\section{$4 \quad$ Research design}

An easily accessible tool for visual analytics is Gapminder (www.gapminder.org). Based on data available from various international organizations, Gapminder allows data to be combined freely in up to five dimensions. An offline version is available, which is handy for school use in cases where sufficient broadband internet access is not available (https://www.gapminder.org/world-offline/). Gapminder also has a specific section for teachers in secondary schools, as well as several documented practice examples from geography education (see Lang, 2012; Jekel, 2014). In general, Gapminder enables learning with diagrams (as opposed to learning from diagrams). This can be considered in line with general tendencies towards learning with (instead of from) diagrams, as identified by Tippett (2016, p. 733).

Based on the assumption that learning with diagrams through one's own creation of representations leads to better learning results, students in secondary education $\left(6^{\text {th }}\right.$ form, aged 16-17) had to develop hypotheses that would explain the varying levels of $\mathrm{CO}_{2}$ emissions. The exact task was: 
"Causes for the variation of $\mathrm{CO}_{2}$ emissions are contested, as they may be linked to very different phenomena. We ask you to find reasons that explain the variation of $\mathrm{CO}_{2}$ emissions between countries, based on data available in Gapminder, and to visualize them adequately.

1. Set the y-axis as $\mathrm{CO}_{2}$ emissions per person; use other available data to find explanations for the varying $\mathrm{CO}_{2}$ emissions. Your aim should be to find a consistent reasoning. Describe clearly all the actions and decisions you take within Gapminder, e.g. each change of variable, indicators etc.

2. Visualize your final result or hypotheses in a way that is convincing (i.e. when presenting your work in class, other students will believe your argument).

3. Share your final graph and hypotheses with the research coordinator."

(Original in German)

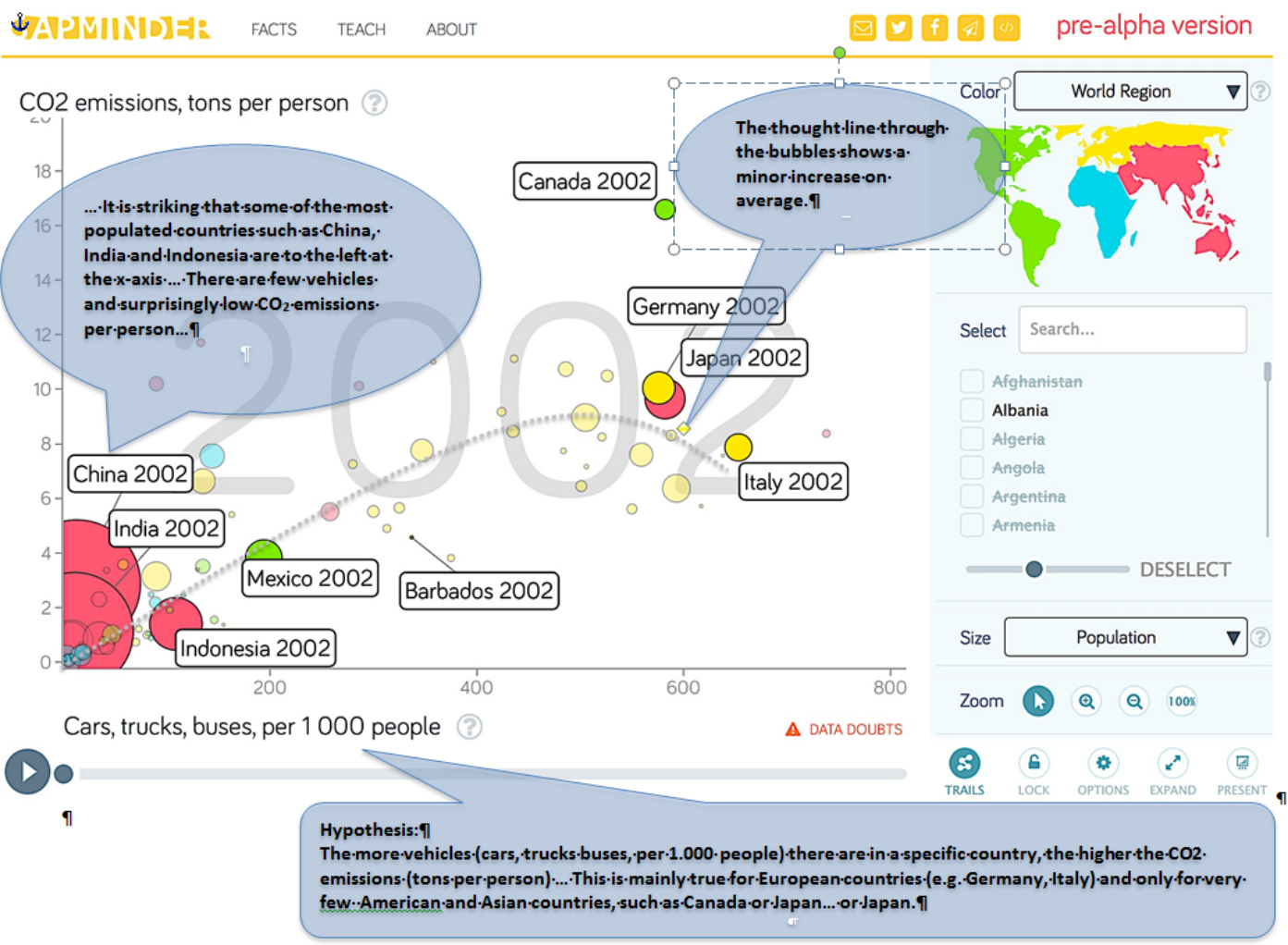

Figure 1: Students' thoughts while developing hypotheses for $\mathrm{CO} 2$ emissions. Transcription \& translation: the authors. 


\section{$5 \quad$ Videography as an analysis tool}

To analyse the videos collected by screen-recording the students' hypothesis-generation process and their verbalized thoughts, we used videography. Videography was selected as a method with an inductive approach, without providing students formally with any orienting theory, but with some general questions in mind (Derry et. al., 2010, pp. 9-10; Abend et al., 2012). The most important aspect of videography is capturing the video itself, so using the camera as a medium for data collection from moving images. Thus, the researcher is able to interpret the data corpus, to recognize patterns in it, and to analyse the interactions with and actions within a video (Tuma et al., 2013, p. 12). The aim is to focus on how actors proceed during an (inter-)action. In our case, the action was the process of hypothesis-generation (Tuma et al., 2013, p. 14).

For the whole process of inquiry, Derry et al. list the following steps:

(a) planning a study, (b) shooting original footage, (c) choosing one or more clips from a corpus of such footage, (d) focusing on the selected video clip or clips in appropriate ways depending on the researcher's goals, (e) developing final products for presentation. (Derry et al., 2010, p. 8)

After the video recording, the first step is to get an overview of the data corpus (Tuma et al., 2013, p. 17), so the second step is to make a selection. This process has to focus on specific information expected from the videos, keeping in mind a theoretical framework, and guiding and research questions. In order to make a selection from the data, the video is segmented, each segment representing an incident (Derry et al., 2010, p. 6).

In our case, one segment contains the searching process itself (that is, the search for an indicator that explains $\mathrm{CO}_{2}$ emissions), or the selection of an indicator by the students. This means that the observation of the animation in Gapminder also corresponds to one segment.

The next step, the indexing, involved making field notes on the recording of the video. Rather than being made during the actual recording, notes were made while viewing the videos. The students made time-indexed notes if something striking or relevant to the learning process took place (Derry et al., 2010, p. 18). More important was the content log, which included the actions carried out by the student within the segments. In addition, the segments were transcribed. For the analysis of the segments, we chose to create a table, which combined a timeline, indexing, a content log, and the key element - i.e. the transcription. To note down comments or interpretative observations, an extra column was added.

A pre-test with five first-semester students of geography and economics who had no prior knowledge of Gapminder was conducted in early 2016. This led to minor changes in the task description, and to a stronger emphasis on expressing thoughts verbally for recording. The final testing with nine students from two secondary schools was conducted in November and December 2016. 


\section{Quantitative results}

Looking at the data collected, we were able to identify 164 segments where students switched between activities (orientation, indicator search \& selection, hypothesis-generation). In total, 57 different indicators were selected, out of which 26 hypotheses were generated. 35 of the selections were considered to be of no use by the students themselves or because the researcher hinted at issues at the end of the segment which would not lead to reasonable hypotheses for the explanation of $\mathrm{CO}_{2}$ emissions per person.

The time taken to complete the task varied between $22^{\prime} 28^{\prime \prime}$ and 39'26", thus indicating a potential for use within a typical classroom lesson. Th time needed, however, has not been directly correlated to the quality and quantity of results or spoken text.

Students had support in completing the data task. In 69 cases, the researcher supported them in terms of content, asking clarifying questions ('How does $\mathrm{CO}_{2}$ get into the atmosphere?', 'What are the processes leading to the development of $\mathrm{CO}_{2}$ ?'). This support was only given when students seemed confused, or realized that they were going down the wrong avenue. One of the main reasons for confusion was the difference between total $\mathrm{CO}_{2}$ emissions per country and $\mathrm{CO}_{2}$ emissions per person per country.

Despite being reasonably new to Gapminder or similar tools (this was the students' first hands-on experience), students found the interface reasonably intuitive.

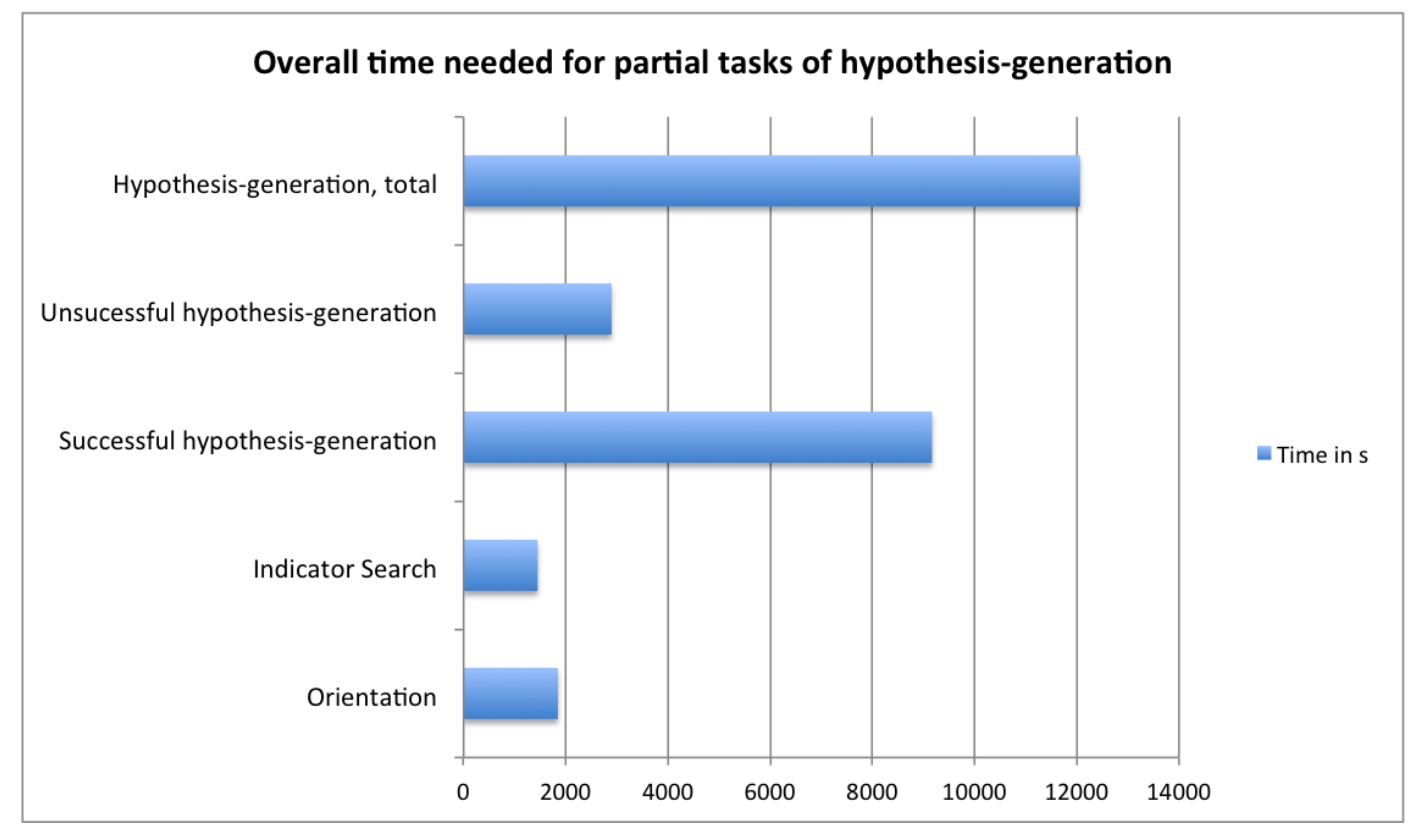

Figure 2: Distribution of time for tasks within Gapminder.

For easier comprehension, the process of hypothesis-generation was divided into 4 stages. 
- Orientation here describes a general orientation on indicators / data rows available within the Gapminder platform.

- Indicator search was deemed relevant when a student searched for specific indicators/rows of data.

- Unsuccessful hypothesis-generation denotes a process in which a student selected indicators, but the data (or visualization) did not lend itself to the formulation of a hypothesis, or the formulation was clearly based on co-variation instead of correlation.

- Successful hypothesis-generation denotes a direct correlation suspected by a student between the indicators displayed, and the student formulated a hypothesis. However, many students developed more than one hypothesis, and selected one of these as their final hypothesis.

It may be noted that familiarization time could be reduced if Gapminder is used as a standard tool for data-based learning in different subjects throughout their education. In our case, this was the students' first contact with data available in Gapminder, as well as with the visualization strategies possible in Gapminder. We would therefore anticipate a greater success rate with better preparation and tool familiarity.

\section{Qualitative results: Common Strategies and Problems}

We first noted that one of the major problems was that students had no knowledge of the form taken by a hypothesis, i.e. the basic structure of a hypothesis (if - then). This may be due to known deficiencies in the Austrian school system, which is knowledge- and not process-oriented, a problem that needs to be addressed urgently. A second common problem was that students needed a significant amount of help with the meaning of absolute vs. relative values (for example: Total consumption of oil vs. Consumption per person). Looking at this problem was beyond the scope of this research.

Concerning common strategies, the following observations can be made:

- Students left the size of 'bubbles' unchanged for their hypothesis-generation through all the segments, meaning that the bubble size reflected the total population

- The general approach then was to identify a) some of the largest bubbles (as in Figure 1), i.e. China, India, Indonesia, US, Russia; b) outliers (in the case of $\mathrm{CO}_{2}$ emissions, the United Arab Emirates, Kuwait and the US).

These selections were done mostly visually, and not by searching for and selecting specific countries (as is also implemented in Gapminder through the list of countries).

- In most segments used for hypothesis-generation, the timeline animation was used to identify developments for specific indicators.

- Students were generally not content with the first hypothesis generated, but usually developed several hypotheses before returning to earlier ones as their final result. 
The above results show great similarity to earlier assumptions (Jekel 2014): that, as a guideline, using 3 indicators is enough for the development of hypotheses (i.e. set one axis as the explanandum, and use another indicator + time for hypothesis-generation). It may be argued that the other two dimensions available (bubble size and colour, both of which can be used to depict each available data row) are only useful for the final visualization of a hypothesis / argument. Using all five possible dimensions at the same time clearly confuses first-time users; in our case study, it was the students' own decision to use only three indicators according to the structure described above. If we were to run similar projects in the future, a basic introduction to visualization might be useful.

The subject of $\mathrm{CO}_{2}$ emissions was loaded with prior knowledge, both from general media coverage, as well as from the secondary-school curriculum, mainly in the subjects of Biology and Geography \& Economics. This may explain why the final hypotheses were all closely linked to energy consumption. According to the students, $\mathrm{CO}_{2}$ emissions are dependent on (final hypothesis):

... coal consumption per person, tons in oil eqv. (Video 1)

... oil consumption per person, tons (Videos 2 und 9)

... energy use per person, tons in oil eqv. (Video 3)

... cars, trucks, buses per 1000 people (Videos 4, 5, 6 and 7)

... energy use, tons in oil (Video 8).

The link to the students' prior knowledge of the subject, however, was usually not clear-cut or direct, as can be shown by the transcription of video 9 (translation: authors):

Because, hmm, [...] coal-based power plants [...] so because there are coal-based power plants [...], and $[\ldots]$ because of them mmb [...] because they burn more and more, more emissions are there. [...] That is eh, hmm [...] I think, this goes hand in hand [...] because [...] as far as I know [...] burning coal and coal-fired power plants, these are those with most emissions, blowing out [...]. I can't say for sure, but I believe it is like that, isn't it?

This type of pre-knowledge is clearly very much related to public discussion in the media, as well as, quite possibly, to secondary education. It shows the possibility of re-using knowledge in hypothesis-generation, albeit in quite a laborious fashion. This difficulty may stem from the compartmentalization of school subjects, e.g. students are seldom challenged to think across subjects in Austrian schools. A different approach - also from video 9 - shows a link to personal (holiday) experiences:

[In Dubai] One can see many people in the streets [...] where we can expect that the family [...] has no money problems at home [...] and I think that these are those people who looked for an oil well [...] very early, or who have made one their own [...] as the Arab Emirates had a tremendous boom. This is one of the most and fastest developed metropoles in the world [...] Dubai for example, or Abu Dhabi.

As well as showing the student's imagination (a rich family, fashionably dressed, with a big car, literally have an oil well in their back yard), this comment strongly suggests an amalgam of the public image of a specific country, personal experience, and interpretation based on something very different from $\mathrm{CO}_{2}$ emissions: the student argues from fashion to $\mathrm{CO}_{2}$ emissions. However weird this may sound, there are useful points in a statement like this 
one, which takes the argument into the social sphere. Arguments such as this one also illustrate how specific indicators may co-variate, but may not correlate at the same time.

What is striking in students' arguments for hypotheses is the complete absence of geo-spatial arguments. Few students related their prior knowledge to spatial distribution of resources, as did the student just quoted, or linked these, as the student in Video 8 did, as a means to search for relevant indicators:

[...] economy [...] or education, possibly not, energy. Ah, coal, this would be interesting for China. China has large coal resources. I'd say in total, not per person.

(After this statement, the indicator 'Coal consumption, tons in oil equivalent' and the country China were selected for further visual analysis.)

While again there are assumptions that may or may not be true (for example that the place of resources is the same as the place of consumption), it is important to note that space is very seldom used in reasoning, and if it is, the reasoning is often false. Finally, in practically all segments devoted to hypothesis-generation, the interactivity of the visualization was clearly used as a basis for argumentation and hypothesis-development. This is true for the selection, zooming and use of the timeline for the development of specific indicators.

\section{Discussion}

It is the last point, interaction, that clearly relates to earlier research by Tippett (2016) and Gobert \& Clement (1999). Individually interacting with information by producing diagrams seems to foster a better understanding than producing hypotheses from pre-given diagrams. The results also support the viability of using ideas from visual analytics (Andrienko et al, 2010) at secondary-school level. At the same time, prior assumptions of working with 3 indicators (1 explanandum, 2 indicators as explanans; Jekel, 2014) for hypothesis-generation are supported. Further indicators may later be used in the communication aspect of hypothesis-generation, i.e. developing persuasive and convincing visual representations via discursive processes, which is part of the concept of innovativeness formulated by Gryl (2013) and Jekel et al. (2015).

For the structuring of phenomena for hypothesis-generation as well as the communication of hypotheses developed, a few pointers can be derived from the data analysed:

1. A more coherent approach to hypothesis-generation in science education is needed to make full use of the tools available. Currently, data-based hypothesis-generation has not been taught structurally, at least in Austrian schools. We deem this a necessary precondition for the development of innovativeness in the field of technological innovation, as presented in Shavinina (2013).

2. Specific attention on the part of teachers has to be given to the difference between co-variation and correlation, and to things as simple as absolute vs. relative data. These need to be addressed in both initial teacher training and in teachers' ongoing professional development. 
3. At the same time, it may be noted that spatial approaches and spatial thinking skills have clearly been missing. We do not argue for an exclusive return to the spatial approach, as this would clearly exclude innovation in the social domain as argued by Schmitz et al. (2016), as well as in the Spatial Citizenship approach (Gryl \& Jekel, 2012), but we do think that, where applicable, greater emphasis needs to be placed on the structural ideas behind spatial thinking and spatial reasoning.

4. Where the communication aspect of innovativeness is concerned, we draw attention to a profound need to include basic aspects of graphics in secondary education. This supports not only hypothesis-generation, but also other tasks in secondary education, including working with quantitative data, i.e. in pre-scientific papers to be written higher secondary education (ages 14-18).

Further analysis of the data is in preparation which will surely uncover more detailed ideas and guidelines for teachers. At the moment, however, we can support the statement that the Gapminder platform lends itself reasonably well to the generation of hypotheses and communication part of an education for innovativeness in the techno-rational sphere.

\section{Acknowledgement}

Our thanks for supporting this research go to teachers and students at the Gymnasium BRG Hallein and the Herz-Jesu Gymnasium, Salzburg, Austria.

\section{References}

Abend, P., Thielmann, T., Ewerth, R., Seiler, D., Mühling, M, Döring, J. Grauer, M. \& Freisleben, B. (2012), Geobrowsing Behaviour in Google Earth. A semantic Content Analysis of On-Screen Navigation. In: Jekel, T., Car, A., Strobl, J. \& Griesebner, G., GI_Forum 2012: Geovisualization, Society \& Learning. Berlin \& Offenbach, Wichmann, 2-13.

Andrienko G., Andrienko N., Demsar U., Dransch, D, Dykes, J. , Fabrikant S.I., Jern M., Kraak M-J. Schumann H. \& Tominski, C. (2010) Space, time and visual analytics, International Journal of Geographical Information Science, 24:10, 1577-1600, DOI: 10.1080/13658816.2010.508043.

Butcher, K. R. \& Kintsch, W. (2004), Learning with Diagrams: Effects on Inferences and the Integration of Information. In: Blackwell et al. (Eds.) Diagrams 2004. Berlin-Heidelberg: Springer, 337-340.

Derry S. J., R. D. Pea , B. Barron, R. A. Engle, F. Erickson, R. Goldman, R. Hall, T. Koschmann, J. L. Lemke, M. G. Sherin \& Sherin, B.L. (2010): Conducting Video Research in the Learning Sciences: Guidance on Selection, Analysis, Technology, and Ethics. Journal of the Learning Sciences, 19:1, 3-53. Gartner, G. (2009), Web Mapping 2.0. In: Dodge, M., Kitchin, R. \& Perkins, C. (Eds.), Rethinking Maps. New Frontiers in Cartographic Theory. Routledge, London, 68-82.

Gobert, J. D. \& Clement, J.J. (1999), Effects of Student-Generated Diagrams versus Student Generated Summaries on Conceptual Understanding of Causal and Dynamic Knowledge in Plate Tectonics. Journal of Research in Science Teaching, 36, 1, 39-53.

Gordon, E., Elwood, S. \& Mitchell, K. (2016). Critical Spatial Learning: Participatory Mapping, Spatial Histories, and Youth Civic Engagement. Children's Geographies, 558-572 doi: 10.1080/14733285.2015.1136736. 
Gryl, I. (2013): Alles neu - innovativ durch Geographie- und GW-Unterricht?. GW-Unterricht 131, 1627.

Gryl, I., \& Jekel, T. (2012): Re-centering GI in secondary education. Towards a spatial citizenship approach. Cartographica 47, 1, 18-28.

Hegarty, M. (2004). Dynamic Visualisations and Learning: Getting to the Difficult Questions. Learning and Instruction 14 (3): 343-351. Retrieved from http://dx.doi.org/10.1016/j.learninstruc.2004.06.007.

Jekel, T. (2014): Using a visual analytics approach for hypothesis generation. In: Jekel, T., E. Sanchez, I. Gryl, C. Juneau-Sion \& J. Lyon (Eds.): Learning and Teaching with Geomedia. Cambridge: Cambridge Scholars Publishing, 176-186.

Jekel, T., N. Ferber \&Stuppacher, K. (2015): Innovation vs. Innovativeness: Do we support our students in reinventing the world? GI-Forum 3, 373-381.

Jekel, T., Gryl, I., \& Schulze U. (2015), Education for Spatial Citizenship. In: Muniz-Solari, O., Demirci, A., van der Schee, J., Geospatial Technologies and Geography Education in a Changing World. Tokyo: Springer, 35-49.

Lang, R. (2012) Using Gapminder. GW-Unterricht, 126, 76-87.

Marsh, M, Golledge, R. \& Battersby S.E. (2008), Geospatial Concept Understanding and Recognition in G6-College Students: A Preliminary Argument for Minimal GIS. Annals of the Association of American Geographers, 97, 4, 696-712.

NRC (National Research Council) (2006), Learning to Think Spatially: GIS as a Support System in the K-12 Curriculum. Washington, DC: National Academies Press.

Scharf, C., Schmitz, S. \& Gryl, I (2016), Innovativeness as Fresh Ground: From an Old Buzzword to New Praxis. GI_Forum, 4, 1, 250-261.

Shavinina, L. V. (Ed., 2013), The Routledge International Handbook of Innovation Education. New York: Routledge,

Sinton, D.S., Bednarz, S., Gersmehl, P, Kolvoord, R., Uttal, D \& Dulli, Z (2013), The People's Guide to Spatial Thinking. Washington D.C.: National Council for Geographic Education.

Sui, D., Elwood, S. \& Goodchild, M. (Eds, 2013) Crowdsourcing Geographic Knowledge. Volunteered Geographic Information (VGI) in Theory and Practice. Dordrecht: Springer.

Tippett, C.D. (2016) What recent research on diagrams suggests about learning with rather than learning from visual representations in science. International Journal of Science Education, 38:5, 725746, DOI: 10.1080/09500693.2016.1158435.

Traun, C., Jekel, T., Loidl, M., Vogler, R., Ferber, N. \& Gryl, I. (2013): Neue Forschungsansätze der Kartographie und ihr Potential für den Unterricht. GW-Unterricht 129, 4, 5-17.

Tuma, R., B. Schnettler \& Knoblauch, H. (2013): Videographie. Einführung in die interpretative Videoanalyse sozialer Situationen. Wiesbaden: Springer VS. 